\title{
A METHOD TO CALIBRATE BEAM POSITION MONITOR AT HLS 200 MeV LINAC*
}

\author{
J. H. Li ${ }^{\#}$, B. G. Sun, D. H. He, P. Lu, Y. Wang, J. H. Wang, K. Jin, Y. Cao, P. Zheng \\ NSRL, University of Science and Technology of China, Hefei, Anhui 230029, P.R.China
}

\begin{abstract}
In order to improve injection efficiency of HLS $200 \mathrm{Mev}$ LINAC, we redesign a new strip line beam position monitor system, which is consisted of a strip line structure and a signal processing system. We decide on an online calibration method based on beam to find out the geometry centre displacement and relative gain offset. Before the BPM testing bench has been prepared, we make a simulation based on the model accounted for all factors influencing signal amplitudes and get the calibrating results. At last, we analyze the nonlinearity effect on the calibration results.
\end{abstract}

\section{INTRODUCTION}

In order to improve the injection efficiency and the performance of beam position measurement, we redesign a new beam position monitor system for HLS $200 \mathrm{MeV}$ Linac. The new system is consisted of a strip line structure and a signal processing system, which is noninterceptive, good in precision, and facilitates digitalizing the measurement results. The system needs calibrating because of pickup centre displacement and nonlinearity caused by machining, installment, cable matching, and signal processing circuits. We give out a calibration model accounting for the factors influencing signal amplitudes based on on-line calibration. Before the BPM testing bench has been prepared, we make a simulation based on the model and get the calibrating results. At last, we analyze the nonlinearity effect on the calibration results.

\section{STRIPLINE BPM STRUCTURE}

Beam position monitors at HLS Linac and transfer line will deliver the information about the transverse positions of the beam passing by. The original stripline BPM for HLS LINAC has an azimuthal angle of 20.8 degrees with a length of $300 \mathrm{~mm}$ and an inner radius of $22 \mathrm{~mm}$. According to the simulation results of CST Microwave Studio, the character impedance of the original structure is $48.7 \Omega$ in sum mode, $47.2 \Omega$ in dipole mode, and $46.7 \Omega$ in quadrupole mode. But the amplitude of pick up

\footnotetext{
* Supported by Specialized Research Fund for the Doctoral Program of Higher Education, Project of building a highlevel university well-known both in China (KY2901), and the Grant of 863 Program of China (863-410-8-2)

\# jhli@mail.ustc.edu.cn
}

signals is not large enough to deduce the beam positions.

We redesign a new strip line structure for HLS $200 \mathrm{MeV} \mathrm{Linac}{ }^{[1]}$, which is 60 degrees in azimuthal angel with an inner radius of $19 \mathrm{~mm}$ and an length of $183.8 \mathrm{~mm}$ (7/4 wavelength according to HLS Linac RF frequency $2.856 \mathrm{GHz})$. Figure1 shows the new designed electrode structure for HLS $200 \mathrm{MeV}$ Linac. The character impedance of the new structure is $59.7 \Omega$ in sum mode, $47.6 \Omega$ in dipole mode and $42.8 \Omega$ in qaudrupole mode. The discrepancy of characteristic impedance among different modes is larger because of the stronger coupling between the electrodes of the new BPM.

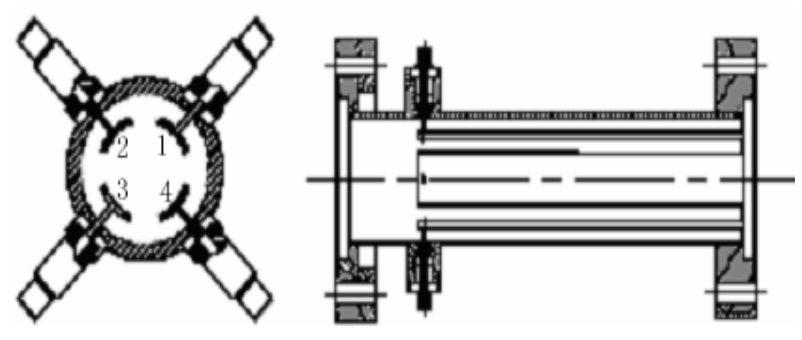

Figure1: Stripline BPM structure.

\section{CALIBRATION METHOD}

When it comes to the calibration scheme, we determine a beam based on-line calibration of the beam position monitor system for HLS $200 \mathrm{MeV}$ Linac. According to Kotaro Satoh and Masaki Tejima ${ }^{[4]}$, we get the calibration parameters based on a calibration model and a method of multi-measurement and function fitting, which can reduce the calibration errors than single measurement method. Additionally, the beam based calibration method has an advantage over the traditional antenna scanning and wire scanning methods ${ }^{[3]}$, which use some simulation signals other than beam signals themselves and are prone to errors caused by electric centre displacement.

\section{CALIBRATION MODEL}

According to Kotaro Satoh and Masaki Tejima $^{[4]}$, the 4 strip line pickup signals processed can be expressed as

$$
V_{i}=g_{i} \cdot q \cdot F_{i}(x, y), \quad \mathrm{i}=1,2,3,4
$$

Where $\mathrm{q}$ is beam charge, $\mathrm{x}$ and $\mathrm{y}$ is horizontal and vertical beam positions respectively relative to geometrical monitor centre, $F_{i}(x, y)$ stand for pickup 
response functions and are normalized as $F_{i}(0,0)=1$, $g_{i}$ stand for the relative overall gains of each electrode and $g_{1}=1$.

Firstly, we calculate the pickup response functions $F_{i}(x, y)$ by Mafia simulation and function fitting. The electrode signals induced by ultrarelativistic beam can be expressed as ${ }^{[5]}$

$$
F_{1}(x, y)=1+\sum_{k=1}^{\infty} r^{k}\left(a_{i}(k) \cos k \theta+b_{i}(k) \sin k \theta\right)
$$

Where $\theta$ stands for the azimuthal angle of each electrode. The pickup structure for HLS $200 \mathrm{MeV}$ Linac has a symmetry as $\theta=45^{\circ}$ and $F_{1}(x, y)=F_{1}(y, x)$. So equation 2 can be expressed as

$$
\begin{aligned}
F_{1}(x, y)= & 1+a(x+y)+b x y \\
& +c\left(x^{3}+y^{3}\right)+d\left(x^{2} y+x y^{2}\right)
\end{aligned}
$$

Table 1 gives out the pickup response of electrode through $\mathrm{Mafia}^{[6]}$ simulation about stripline pickup for HLS $200 \mathrm{MeV}$ Linac.

Table 1: Relations between beam potions and electrode responses.

\begin{tabular}{|c|c|c|c|}
\hline$(\mathrm{x}, \mathrm{y})$ & $(3,0)$ & $(3,3)$ & $(0,3)$ \\
\hline $\mathrm{F}_{1}$ & 1.132 & 1.347 & 1.132 \\
\hline$(\mathrm{x}, \mathrm{y})$ & $(-3,3)$ & $(-3,0)$ & $(-3,-3)$ \\
\hline $\mathrm{F}_{1}$ & 0.985 & 0.978 & 0.869 \\
\hline$(\mathrm{x}, \mathrm{y})$ & $(0,-3)$ & $(3,-3)$ & $(0,0)$ \\
\hline $\mathrm{F}_{1}$ & 0.978 & 0.985 & 1 \\
\hline
\end{tabular}

Making a least chi-square fitting at equation 3 based on table 1 , we get

$$
\begin{aligned}
F_{1}(x, y)= & 1+0.0746(x+y)+0.0068 x y \\
& -0.0048\left(x^{3}+y^{3}\right)+0.0016\left(x^{2} y+x y^{2}\right)
\end{aligned}
$$

Because of symmetry of the pickup structure, we can also get the other three response functions as

$$
\left\{\begin{array}{l}
F_{2}(x, y)=F_{1}(-x, y) \\
F_{3}(x, y)=F_{1}(-x,-y) \\
F_{4}(x, y)=F_{1}(x,-y)
\end{array}\right.
$$

We can get a set of electrode signals after measuring $\mathrm{m}$ times.

$$
V_{i j}=g_{i} q_{j} F_{j}\left(x_{j}, y_{j}\right)=V(i, j ; a)
$$

Where $i=1, \ldots, 4, j=1, \ldots, m, a=\left(g_{2}, g_{3}, g_{4}, q_{1}, x_{1}, y_{1}, \ldots\right.$, $\left.\mathrm{q}_{\mathrm{m}}, \mathrm{x}_{\mathrm{m}}, \mathrm{y}_{\mathrm{m}}\right)$,

Now there are $3 m+3$ parameters to determine and $4 m$ equations. So we can calculate the parameters such as $g_{2}$, $\mathrm{g}_{3}, \mathrm{~g}_{4}, \mathrm{q}_{1}, \mathrm{x}_{1}, \mathrm{y}_{1}, \ldots, \mathrm{q}_{\mathrm{m}}, \mathrm{x}_{\mathrm{m}}, \mathrm{y}_{\mathrm{m}}$ by least chi-square fitting when $m \geq 4$. That is, they make equation 6 minimized.

$$
\chi^{2}(a)=\sum_{i=1}^{4} \sum_{j=1}^{m}\left[V_{i j}-V(i, j ; a)\right]^{2}
$$

\section{CALIBRATION RESULTS AND ANALYSIS}

Since the testing bench of the beam position monitor for HLS $200 \mathrm{MeV}$ LINAC has not been prepared, we use the electrode signals simulated by Mafia instead at present for calibration. Table 2 gives out the relations between beam positions and electrode signals.

Making a least chi-square fitting at equation 5 based on table 2 , we get all the parameters calibrated as table 3 .

Table 2: Electrode responses simulated by Mafia.

\begin{tabular}{|c|c|c|c|c|}
\hline$\left(\mathrm{x}_{\mathrm{j}}, \mathrm{y}_{\mathrm{j}}\right)$ & $(3,0)$ & $(3,3)$ & $(0,3)$ & $(-3,3)$ \\
\hline \multirow{4}{*}{$\mathrm{V}_{\mathrm{ij}}$} & 1.132 & 1.347 & 1.132 & 0.985 \\
\cline { 2 - 5 } & 0.978 & 0.985 & 1.132 & 1.347 \\
\cline { 2 - 5 } & 0.978 & 0.869 & 0.978 & 0.985 \\
\cline { 2 - 5 } & 1.132 & 0.985 & 0.978 & 0.869 \\
\hline \multirow{3}{*}{$\left(\mathrm{x}_{\mathrm{j}}, \mathrm{y}_{\mathrm{j}}\right)$} & $(-3,0)$ & $(-3,-3)$ & $(0,-3)$ & $(3,-3)$ \\
\hline \multirow{3}{*}{$\mathrm{V}_{\mathrm{ij}}$} & 0.978 & 0.869 & 0.978 & 0.985 \\
\cline { 2 - 5 } & 1.132 & 0.985 & 0.978 & 0.869 \\
\cline { 2 - 5 } & 1.132 & 1.347 & 1.132 & 0.985 \\
\cline { 2 - 5 } & 0.978 & 0.985 & 1.132 & 1.347 \\
\hline
\end{tabular}

Table 3: Fitting values and preset values.

\begin{tabular}{|r|c|c|c|}
\hline $\begin{array}{r}\text { Preset } \\
\mathrm{X}_{\mathrm{j}} \mathrm{Y}_{\mathrm{j}}\end{array}$ & $(3,0)$ & $(3,3)$ & $(0,3)$ \\
\hline $\begin{array}{r}\text { Fitting } \\
\text { values }\end{array}$ & $(3.294,0.012)$ & $(3.359,3.359)$ & $(0.012,3.294)$ \\
\hline $\begin{array}{r}\text { Preset } \\
\mathrm{X}_{\mathrm{j}} \mathrm{Y}_{\mathrm{j}}\end{array}$ & $(-3,3)$ & $(-3,0)$ & $(-3,-3)$ \\
\hline $\begin{array}{r}\text { Fitting } \\
\text { values }\end{array}$ & $(-3.415,3.392)$ & $(-3.325,0.013)$ & $(-3.418,-3.418)$ \\
\hline $\begin{array}{r}\text { Preset } \\
\mathrm{X}_{\mathrm{j}} \mathrm{Y}_{\mathrm{j}}\end{array}$ & $(0,-3)$ & $(3,-3)$ & $(0,0)$ \\
\hline $\begin{array}{r}\text { Fitting } \\
\text { values }\end{array}$ & $(0.013,-3.325)$ & $(3.392,-3.415)$ & $(0.017,0.017)$ \\
\hline$\sigma$ & \multicolumn{4}{|c|}{0.311} \\
\hline $\begin{array}{c}\text { Preset } \\
\mathrm{q}_{\mathrm{j}}\end{array}$ & 1 & 1 & 1 \\
\hline $\begin{array}{c}\text { Fitting } \\
\text { values }\end{array}$ & 1.0531 .0391 .0531 .0391 .0531 .0381 .0531 .039 \\
\hline$\sigma$ & \multicolumn{4}{|c|}{0.017} \\
\hline$\sigma$
\end{tabular}

$(i=2,3,4, j=1,2, \ldots, 9)$ 
During function fitting we set the resolution for $\mathrm{V}_{\mathrm{ij}}$ as $10^{-3}$, which agrees with the precision for signal processing circuits of HLS Linac beam position monitor system. Based on table 3, the resolution for beam position is $0.3 \mathrm{~mm}$ and the electric centre of strip line structure is $(0.017,0.017) \mathrm{mm}$.

Now we study beam position offset caused by nonlinearity of strip line structure. We only take into account the linear components of equation 4 and get the electrode response function as equation 7 .

$$
F_{1}{ }^{\prime}(x, y)=1+0.0746(x+y)
$$

We can also get

$$
\begin{gathered}
\left\{\begin{array}{l}
F_{2}{ }^{\prime}(x, y)=F_{1}{ }^{\prime}(-x, y) \\
F_{3}{ }^{\prime}(x, y)=F_{1}{ }^{\prime}(-x,-y) \\
F_{4}{ }^{\prime}(x, y)=F_{1}{ }^{\prime}(x,-y)
\end{array}\right. \\
V_{i j}=g_{i} q_{j} F^{\prime}{ }_{j}\left(x_{j}, y_{j}\right)=V(i, j ; a)
\end{gathered}
$$

We make a least chi-square fitting at equation 8 based on equation 7. Table 4 gives out comparative figures which show the effect of nonlinearity.

Table 4: Nonlinearity effect on calibration values.

\begin{tabular}{|c|c|c|}
\hline$\sigma$ & $\sigma_{x j, y j}$ & $\sigma_{q j}$ \\
\hline Equation 7 & 1.418 & 0.030 \\
\hline Equation 4 & 0.311 & 0.017 \\
\hline
\end{tabular}

From table 4, we conclude that nonlinearity has an impact of about a magnitude degree on the beam position resolution. So equation 4 describes electrode response better than equation 7 .

\section{CONCLUSION}

Before the BPM testing bench has been prepared, we make a simulated beam-based calibration of stripline beam position monitor for HLS $200 \mathrm{MeV}$ Linac through a model accounting for the factors influencing electrode signal amplitudes. Adopting the method of Mafia simulation and least chi-square fitting, we conclude the beam position resolution is $0.311 \mathrm{~mm}$ and nonlinearity has an effect of about a magnitude degree on beam position resolution. The simulated results are good enough for HLS LINAC BPM. And we expect a calibration on testing bench and a calibration after installation in future.

\section{REFERENCES}

[1] LI Ji-Hao, SUN Bao-Gen, HE Duo-Hui. etc. Design and Simulation of HLS LINAC Beam Position
Monitor. Has been accepted by Nuclear Science and Technique.

[2] P.Evtushenko, A.Büchner, H.Büttig, etc. STRIPLINE BEAM POSITION MONITORS FOR "ELBE". DIPAC 2001 Proceedings - ESRF, Grenoble.

[3] D. Wang, B. Binns, M. Kogan, A. Zolfaghari, Wire Setup Calibration of Beam Position Monitors, Proceedings of 1995 Particle Accelerator Conference.

[4] Kotaro Satoh and Masaki Tejima, Recalibration of Positon Monitors with Beams, Proceedings of 1995 Particle Accelerator Conference.

[5] Sergey S. Kurennoy, Nonlinearities and effects of transverse beam size in beam position monitors, PHYSICAL REVIEW SPECIAL TOPICS ACCELERATORS AND BEAMS, VOLUME 4, 092801 (2001).

[6] Mafia, Version 4.106. 